\title{
El Fomento de la Cultura Emprendedora en el proceso de la Formación Universitaria dentro del Ecosistema Emprendedor
}

\author{
M.Sc. Juan Carlos Arancibia Carpio \\ juancarlosarancibiacarpio@gmail.com \\ Universidad Mayor Real y Pontificia de San Francisco \\ Xavier de Chuquisaca
}

\section{RESUMEN}

La siguiente investigación analiza el fomento de la cultura emprendedora en el proceso de la formación universitaria dentro del ecosistema emprendedor. A través del método descriptivo y cuantitativo realizado en la Carrera de Administración de Empresas, Facultad de Ciencias Económicas y Empresariales de la Universidad San Francisco Xavier de Chuquisaca. Se identifican las principales características de la personalidad que se manifiestan en el modo de pensar y actuar relacionada con la búsqueda y el aprovechamiento de las oportunidades de los estudiantes del cuarto año de la Carrera de Administración de Empresas. Como principal conclusión se establece que, aunque existen capacidades emprendedoras que son innatas a los estudiantes también hay otras que se pueden formar y desarrollar a través de fomentar un proceso de asociación entre el aprendizaje y la experiencia. En este sentido cobra vital importancia la actividad de las asociaciones y fundaciones no gubernamentales que impulsan, el desarrollo y afianzamiento del espíritu emprendedor en los miembros de la sociedad y las políticas públicas que se desarrollan por parte del estado a fin fortalecer el ecosistema emprendedor de la Ciudad de Sucre.

Palabras Claves: Cultura Emprendedora, formación universitaria, ecosistema emprendedor. 


\title{
The Promotion of Entrepreneurial Culture in the process of University Training within the Entrepreneurial Ecosystem
}

\begin{abstract}
The following research analyzes the promotion of an entrepreneurial culture in the process of university education within the entrepreneurial ecosystem. Through the descriptive and quantitative method carried out in the Business Administration Career, Faculty of Economic and Business Sciences of the San Francisco Xavier de Chuquisaca University. The main characteristics of the personality that are manifested in the way of thinking and acting related to the search and use of opportunities of the students of the fourth year of the Business Administration Career are identified. As the main conclusion, it is established that, although there are entrepreneurial capacities that are innate to students, there are also others that can be formed and developed by promoting a process of association between learning and experience. In this sense, the activity of non-governmental associations and foundations that promote, the development and consolidation of the entrepreneurial spirit in the members of society and the public policies that are developed by the state in order to strengthen the entrepreneurial ecosystem of the Sucre city.
\end{abstract}

Key words: Entrepreneurial culture, university education, entrepreneurial ecosystem.

Artículo recibido: 15 abril 2021

Aceptado para publicación: 19 abril 2021

Correspondencia: juancarlosarancibiacarpio@gmail.com

Conflictos de Interés: Ninguna que declarar 


\section{INTRODUCCIÓN}

El emprendimiento en Bolivia hoy en día ha ganado una gran importancia por la necesidad de muchas personas de lograr su estabilidad económica e independencia. Los altos niveles de desempleo, y la baja calidad de los empleos existentes, han creado en las personas, la necesidad de generar sus propios recursos, de iniciar sus propios negocios, y pasar de ser empleados a ser empleadores. Sólo mediante el emprendimiento se podrá salir triunfador en situaciones de crisis. (Rivera Chacon, 2019).

Es menester hacer notar que todo esto, sólo es posible, si se tiene un espíritu emprendedor. Se requiere de una gran determinación para renunciar a la "estabilidad" económica que ofrece un empleo y aventurarse como empresario, más aún sí se tiene en cuenta que el empresario no siempre gana como si lo hace el asalariado, que mensualmente tiene asegurado un ingreso mínimo que le permite sobrevivir. (Grasso Vecchio, 2013).

Fomentar y estimular la creación de nuevas empresas está íntimamente relacionado con un mayor desarrollo económico. Ante esto pasa a ser fundamental el rol del emprendedor en este nuevo andamiaje de la economía mundial y regional. En países en vías de desarrollo, el apoyo logístico, la inversión de capitales y hasta la mano de obra calificada será uno de los puntos en los que el emprendedor se transformará en fundamental para el avance.

Esta importancia del emprendedor dentro de la economía actual, lo transforma en el mayor centro de atención para los tiempos actuales y futuros. La generación de nuevos negocios y ofertas mejoradas, ante los existentes mercados que pueden parecen saturados, acercan emprendedores que promueven la creación de una nueva riqueza. Los emprendedores son importantes para la economía porque al llevar a cabo sus proyectos de negocio fomentan el empleo y el incremento de ingresos a las arcas estatales. Dicha recaudación luego puede ser utilizada para invertir en nuevos emprendedores y continuar ampliando el sector económico y productivo de un país. (Abbate, 2015). En muchos países (casi todos los países Latinoamericanos), para 
muchos profesionales, la única opción de obtener un ingreso decente es mediante el desarrollo de un proyecto propio.

Los gobiernos han entendido muy bien la importancia del emprendimiento, tanto así, que han iniciado programas de apoyo a emprendedores, para ayudarles en su propósito de crear su propia unidad productiva. Casi todos los países, tienen entidades dedicadas exclusivamente a promover la creación de empresas entre profesionales, y entre quienes tengan conocimiento específico suficiente para poder ofertar un producto o un servicio. Ante estas circunstancias económicas, el emprendimiento es el salvador de muchas familias, en la medida en que les permite emprender proyectos productivos, con los que puedan generar sus propios recursos, y les permita mejorar su calidad de Vida.

El emprendimiento es el mejor camino para crecer económicamente, para ser independientes, y para tener una calidad de vida acorde a nuestras expectativas lo cual implica desarrollar una Cultura del Emprendimiento encaminada a vencer la resistencia de algunas personas a dejar de ser dependientes. (Grasso Vecchio, 2013).

Recientemente, Timmons afirmó que "ser un buen emprendedor es un largo proceso de aprendizaje más parecido a una maratón que a una carrera de cien metros planos". La característica fundamental de la mentalidad emprendedora es pensar en términos de oportunidades, no de recursos. (Fuentes Brito, 2010).

Este trabajo de investigación trata como tema central, el fomento de la cultura emprendedora en el proceso de aprender a aprender, indagando aspectos referidos a las características de la personalidad del emprendedor, así como la importancia del aprendizaje. Se investiga también, las acciones que se llevan a cabo la Carrera de Administración de Empresas. La pregunta inicial de esta investigación y que guiará este trabajo es analizar: ¿Cuáles son las características del espíritu emprendedor?

Finalmente, el presente trabajo de investigación busca en primera instancia acceder a una fuente de información documentada sobre el "fomento de la cultura emprendedora", aportando definiciones innovadores sobre el tema en cuestión; dejar las bases establecidas para nuevos estudios que profundicen la investigación a nivel Municipio, Departamento y a nivel nacional, por último que esta investigación sirva como referencia para su aplicación en otras Universidades que tengan características similares a la Ciudad de Sucre.

\section{MÉTODOS Y MATERIALES}


El estudio es descriptivo, cuantitativo. Realizado en la Carrera de Administración de Empresas, Facultad de Ciencias Económicas y Empresariales de la Universidad San Francisco Xavier de Chuquisaca. Dicho estudio se realizó sobre una muestra probabilística aleatoria simple de estudiantes del cuarto año de la Carrera de Administración de Empresas, bajo el criterio de inclusión de ser estudiantes matriculados en la gestión 2020. La aplicación de las encuestas se realizó por medio virtual, de forma anónima y con el consentimiento de los participantes respetando su libertad de decisión para participar.

La técnica utilizada para la obtención de datos estadísticos, medibles y cuantificables es la encuesta que se aplica a 326 estudiantes. El instrumento de recolección de datos consiste en un cuestionario con preguntas cerradas y respuestas dicotómicas y múltiples. La escala utilizada para elaborar el cuestionario es la de Likert. Además, se realizan dos tipos de entrevistas en profundidad a la Directora de Carrera y a las dos docentes de la asignatura de emprendedurismo.

\section{RESULTADOS}

En el presente acápite se presenta el procesamiento y análisis de datos obtenidos a partir de la aplicación de los instrumentos metodológicos (entrevista y encuesta) y del uso de fuentes de información secundaria, con lo cual se pretende iniciar el comienzo de un camino que posibilite realizar futuras investigaciones respecto a la temática abordada.

\section{Características que definen al espíritu emprendedor}

A continuación, se presenta la percepción que tienen los estudiantes de último año de la Carrera de Administración de Empresas respecto a las características que componen al espíritu emprendedor, agrupadas en 4 dimensiones:

- Autoconfianza, creatividad, y responsabilidad del emprendimiento.

- Liderazgo del trabajo en equipo como factor dentro de la sociedad.

- Motivación de logro y la tolerancia hacia la incertidumbre.

- Proactividad como componente del espíritu emprendedor.

\section{Autoconfianza, creatividad, y responsabilidad del emprendimiento.}

La seguridad en uno mismo resulta clave a la hora de emprender. Un emprendedor con autoconfianza es capaz de atraer más oportunidades, incrementando así sus posibilidades de éxito profesional. La creatividad juega un rol fundamental en cuanto a la creación del emprendimiento ya que se convierte en el insumo necesario para 
producir ideas innovadoras o una combinación de ellas. Está relacionada a la originalidad, fluidez, pensamiento divergente y flexibilidad. Pero la creatividad debe estar acompañada por la autoconfianza personal, es decir que la persona debe tener plena confianza en sus capacidades y habilidades a fin poder aplicar sus ideas creativas en el proceso de emprendimiento.

En este sentido, el $81 \%$ de los estudiantes encuestados se ve a sí mismo como una persona creativa, acompañado de un $97 \%$ que manifiesta poseer autoconfianza respecto a sus capacidades y habilidades.

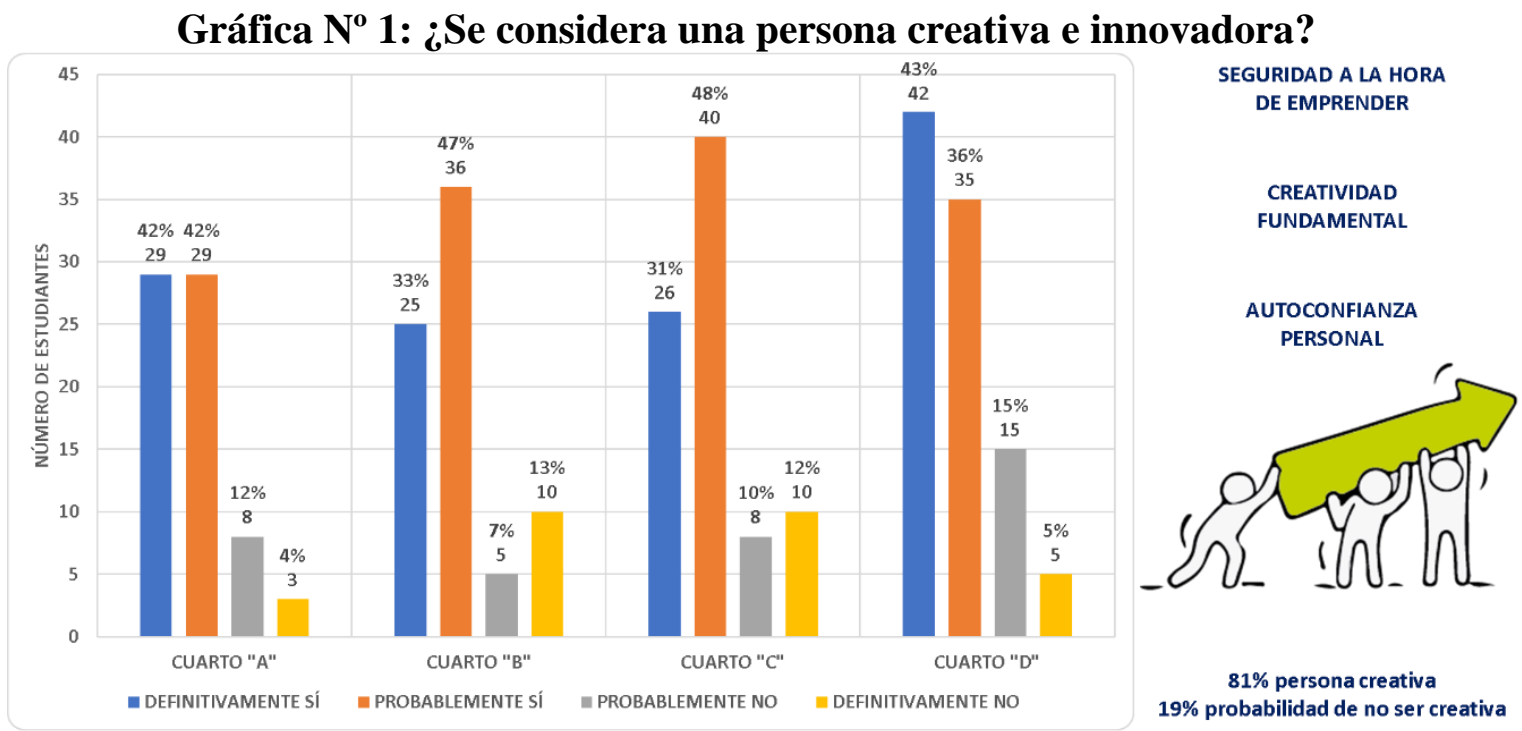

Fuente: Elaborado por el investigador.

En el gráfico puede apreciarse que un $45 \%$ de los encuestados tiene total certeza respecto a ser una persona creativa y el $54 \%$ considera la probabilidad de ser creativos, mientras que el $1 \%$ restante de la muestra reconoce no contar con esas características.

\section{Gráfica $\mathbf{N}^{\circ}$ 2: ¿Tiene confianza respecto a sus habilidades y capacidades} personales? 

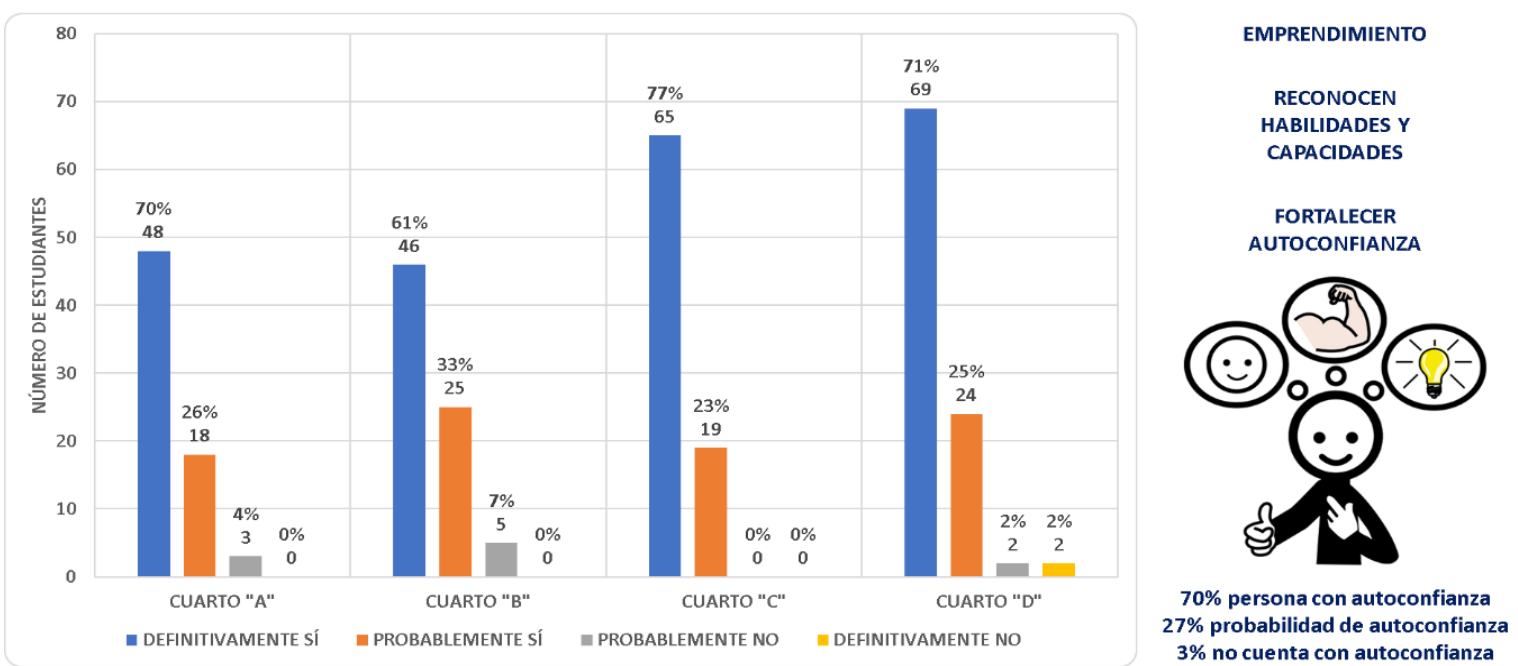

Fuente: Elaborado por el investigador.

En este caso, el gráfico permite ver que un $66 \%$ considera que el emprendimiento les ha permitido reconocer sus habilidades y capacidades, fortaleciendo a su vez la autoconfianza. El 28\% manifiesta una probabilidad respecto al desarrollo de la autoconfianza y el $8 \%$ restante no cuenta aún con dichas características.

Otra característica esencial y que forma parte de los once elementos del perfil del emprendedor establecidos por Andy Freire (2004) es la responsabilidad. En este sentido, se evidencia en los encuestados un alto desarrollo de la dimensión de responsabilidad, mostrando que un $92 \%$ resigna su tiempo libre cuando el trabajo así lo requiere, además de un $92 \%$ que ha establecido de modo claro y preciso los objetivos que desea alcanzar con su emprendimiento.

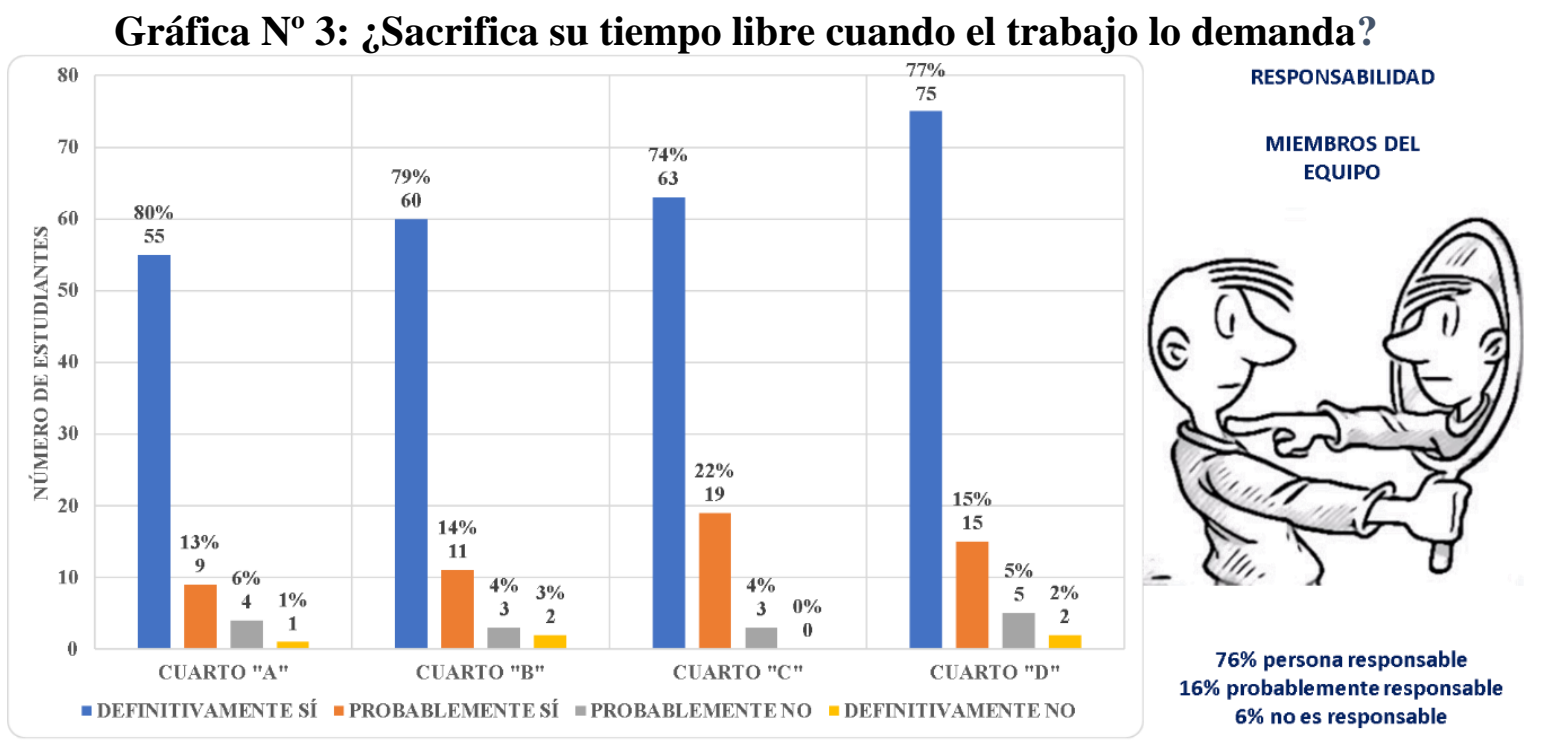

Fuente: Elaborado por el investigador. 
El gráfico permite observar que el $76 \%$ de los emprendedores resignan sin dudar su tiempo libre si el trabajo lo requiere. El 16\% restante de la muestra presenta un cierto grado de incertidumbre respecto a relegar el disfrute de su tiempo libre cuando el trabajo lo demanda. 
Gráfica $\mathrm{N}^{\circ} 4:$ ¿Tiene objetivos claros y definidos respecto a su emprendimiento?

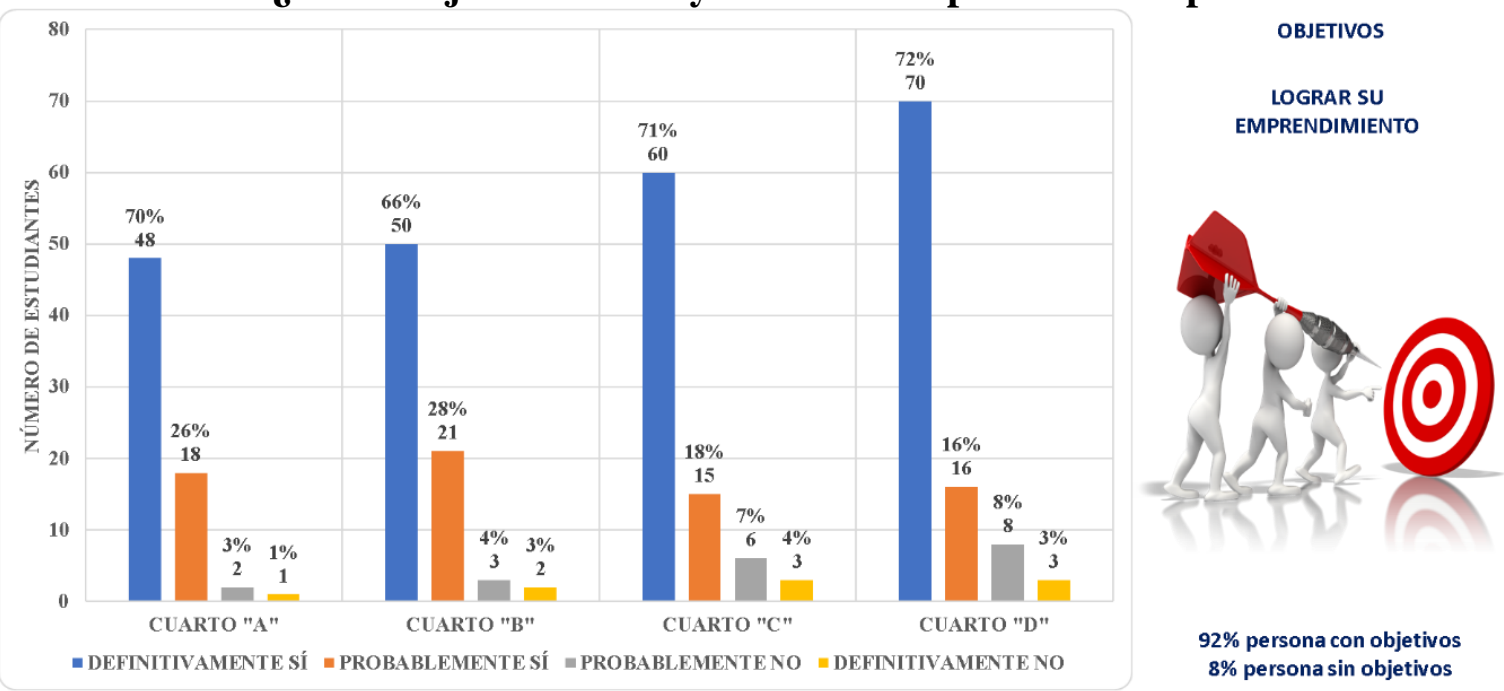

Fuente: Elaborado por el investigador.

En este caso el $92 \%$ de la muestra ha establecido de forma clara y precisa los objetivos a los que pretende lograr con su emprendiemiento. La responsabilidad hace referencia a la capacidad que tiene una persona de identificar y aceptar las consecuencias que tienen sus acciones y como las mismas influirán en la vida de los demás. En el caso de los estudiantes de último año de la Carrera de Administración de Empresas la responsabilidad que asuman frente a su emprendimiento afecta de manera positiva o negativa al resto de los miembros del equipo de trabajo.

\section{Liderazgo del trabajo en equipo como factor dentro de la sociedad.}

Las características sociales son aquellas que se encaminan hacia la búsqueda del bien común, es decir se ponen de manifiesto en el perfil de una persona emprendedora cuando interactúa en su contexto a fin de impulsar el crecimiento sostenible en la región que se desarrolla el emprendimiento.

Algunas de estas características son el liderazgo y el trabajo en equipo. En lo que respecta al liderazgo el $84 \%$ de los estudiantes encuestados valora y fomenta el desarrollo personal y profesional de su equipo de trabajo, lo que permite establecer que ejercen un liderazgo creativo, asociados a la capacidad de transmitir positivismo, autoconfianza y optimismo que lleva a convocar y motivar a los demás.

Por otro lado, se aprecia un alto grado respecto a la orientación hacia el trabajo en equipo. El $84 \%$ de los estudiantes prefiere trabajar con un grupo de personas y el $16 \%$ admite la preferencia por trabajar sólo. 
Gráfica $\mathrm{N}^{\circ}$ 5: ¿Valora y fomenta el desarrollo personal y profesional de su equipo de trabajo?

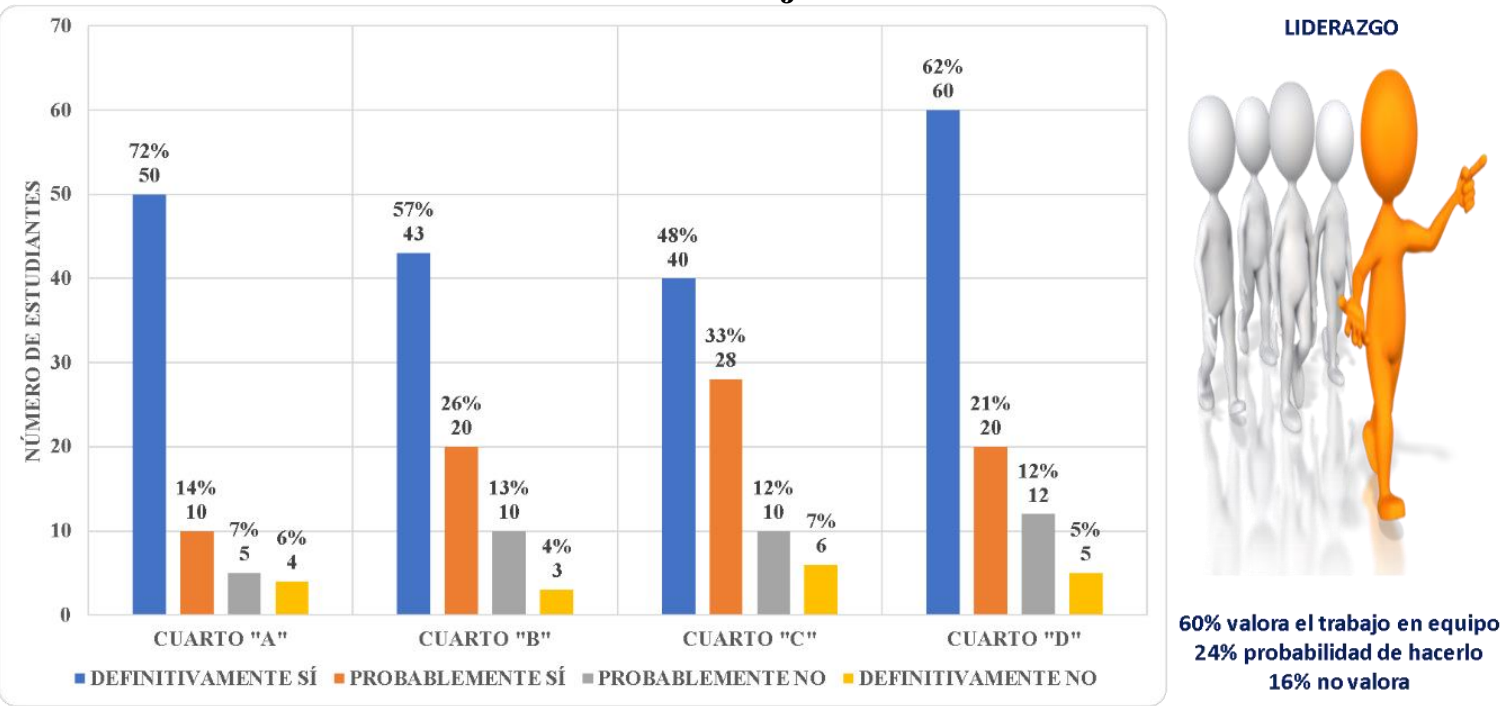

Fuente: Elaborado por el investigador.

Ante la pregunta, el 60\% afirma el hecho de valorar el desarrollo del equipo de trabajo, mientras que el $24 \%$ presenta la probabilidad de hacerlo. El $16 \%$ restante no admite valorar el desarrollo de su personal.

\section{Gráfica $\mathbf{N}^{\circ}$ 6: Respecto a la forma de trabajo. ¿Prefiere trabajar sólo o en equipo?}

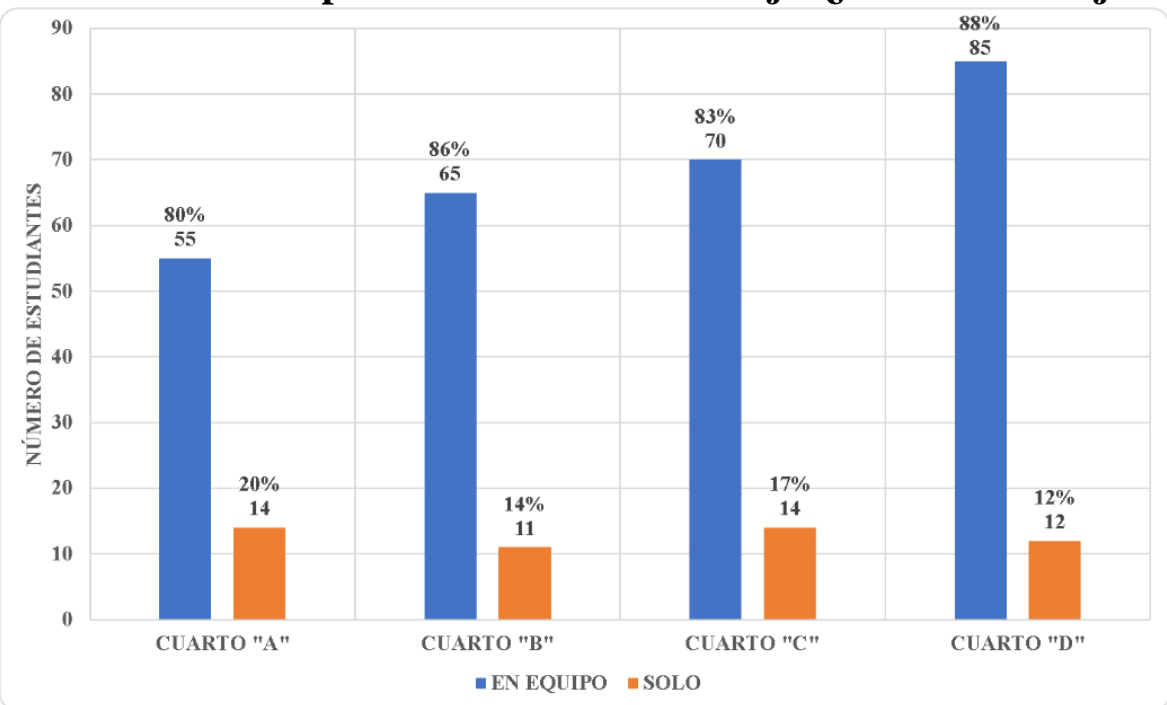

TRABAJO EN EQUIPO

Fuente: Elaborado por el investigador.

El gráfico permite ver que el $84 \%$ de los estudiantes encuestados prefiere realizar el trabajo en equipo y una pequeña parte de la muestra, el 16\% prefiere trabajar sólo. Es así como se puede observar que dentro de las características que componen el espíritu emprendedor, no sólo se favorece el crecimiento personal, sino que además el liderazgo 
eficaz y el trabajo en equipo permite la complementariedad y formación grupal, mostrando que el emprendimiento demanda el desarrollo de capacidades tanto individuales como grupales.

\section{Motivación de logro y la tolerancia hacia la incertidumbre.}

La motivación de logro hace referencia a la necesidad de perseguir y alcanzar objetivos y ascender en la escala del éxito. Los emprendedores se caracterizan por poseer una alta orientación al logro que los impulsa a estar mejorando continuamente.

Esta motivación está dada por la necesidad de obtener resultados satisfactorios toda vez que ejecuten su papel como emprendedor. En este aspecto se aprecia que los emprendedores encuestados cuentan con un elevado grado de motivación hacia la obtención de sus objetivos con un $73 \%$ de respuestas afirmativas.

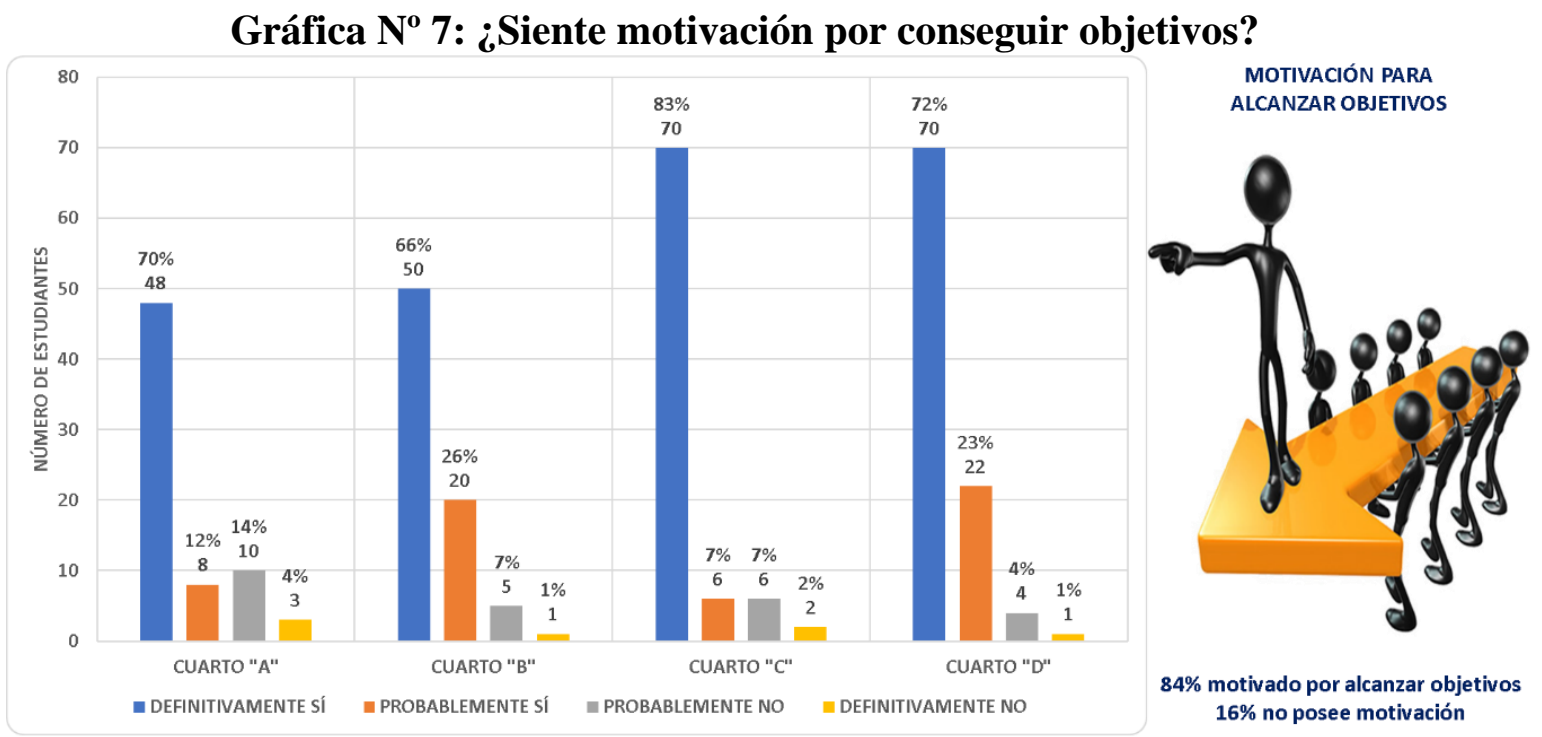

Fuente: Elaborado por el investigador.

El $73 \%$ presenta un alto grado de motivación por alcanzar sus objetivos, un 17\% establece la probabilidad de dicha motivación y un $10 \%$ no posee motivación de logro. En este sentido es importante destacar que al momento de iniciar un emprendimiento pueden darse dos posibilidades. Los emprendimientos por oportunidad, que son aquellos que surgen cuando quienes emprenden han detectado un área o un vacío en el mercado que ellos pueden llenar y capitalizar. Por otro lado, se encuentran los emprendimientos por necesidad que son los que se crean como medio de subsistencia básica del emprendedor. 
Acerca de esto, se establece que los emprendimientos de la Carrera de Administración de Empresas se han desarrollado, en su gran mayoría por oportunidad.

El 37\% de los estudiantes expresan que la creación de su emprendiemiento responde al hecho de desear la realización personal, es decir vivir de lo que les gusta. Un $26 \%$ decidió emprender con el propósito de aplicar sus conocimientos. El 19\% de los encuestados ha comenzado su proyecto con el fin de ser su propio jefe, es decir de ser independiente. Un 18\% de los estudiantes menciona mejorar sus ingresos.

Gráfica $\mathbf{N}^{\circ}$ 8: ¿Cuál de los siguientes motivos lo llevó a emprender?

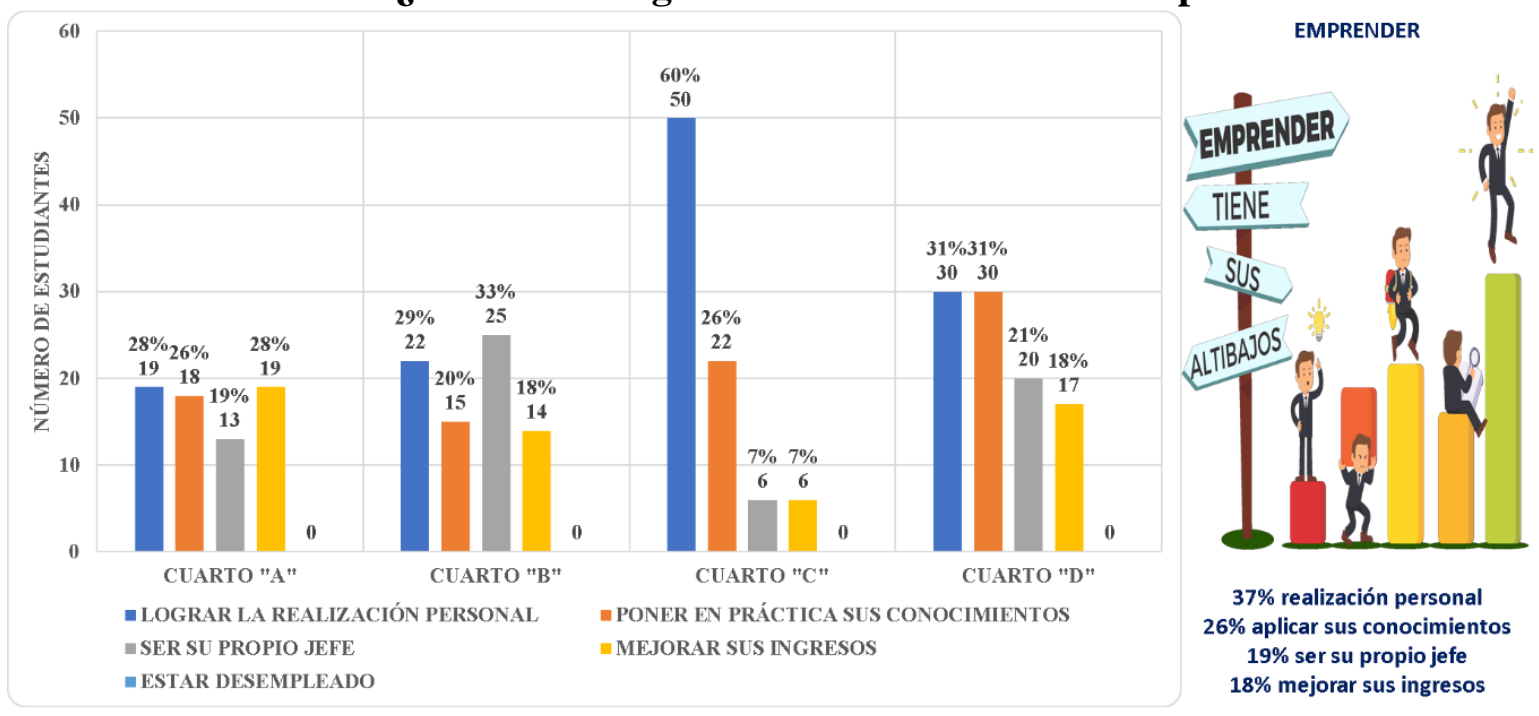

Fuente: Elaborado por el investigador.

Por otra parte, la tolerancia hacia la incertidumbre hace referencia al grado en que una persona acepta o se adapta ante posibles cambios. El individuo que desempeña su actividad en el campo del emprendimiento pretende tomar las decisiones más acertadas con el fin de aprovechar las oportunidades que se puedan presentar, apoyado en su pensamiento creativo y confiando en su capacidades y habilidades.

De los estudiantes encuestados un $60 \%$ demuesta tomar la iniciativa ante situaciones complejas que llevan consigo un grado de incertidumbre. Esto permite ver otra característica de gran importancia que es la capacidad para adaptarse a los cambios. En este caso el $80 \%$ de los estudiantes encuestados han adquirido un rasgo esencial del espíritu emprendedor que es la adaptabilidad. 


\section{Gráfica $\mathbf{N}^{\circ}$ 9: ¿Toma la iniciativa ante situaciones nuevas complejas?}

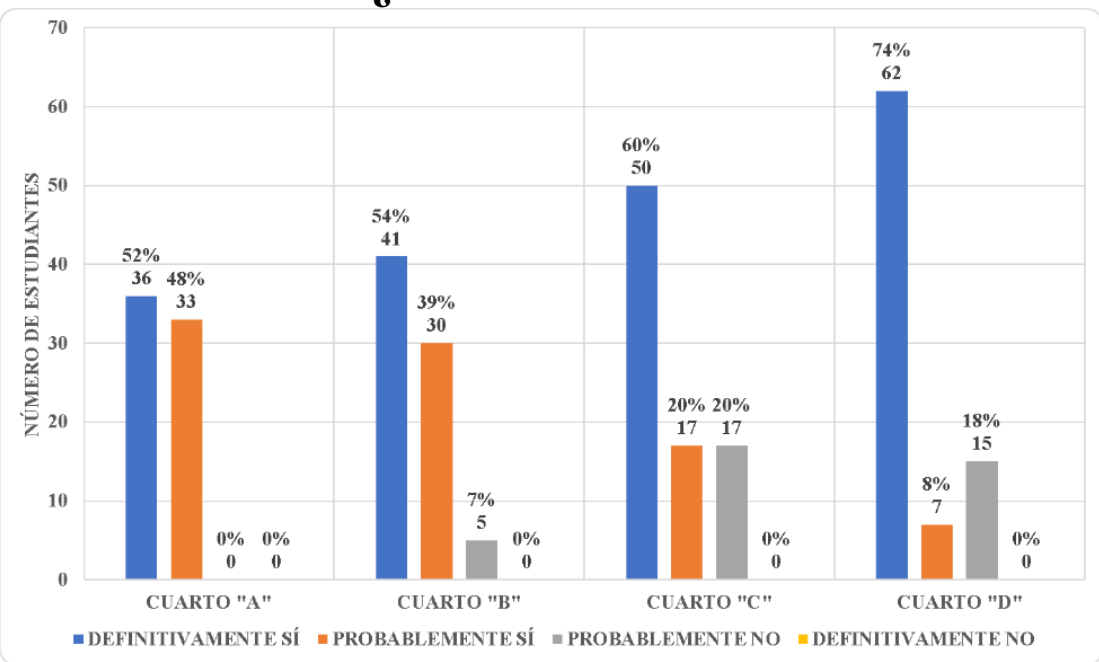

TOMAR INICIATIVA

Fuente: Elaborado por el investigador.

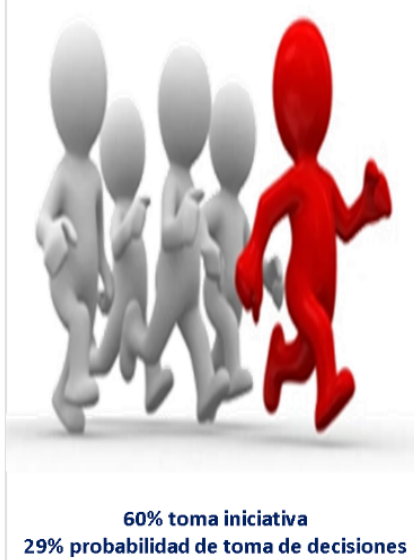

$11 \%$ no asume iniciativa

Del gráfico se desprenden los siguientes resultados: El 60\% toma la iniciativa ante situaciones nuevas, un $29 \%$ probablemente tome la iniciativa en situaciones complejas y el $11 \%$ restante no asume esa posición.

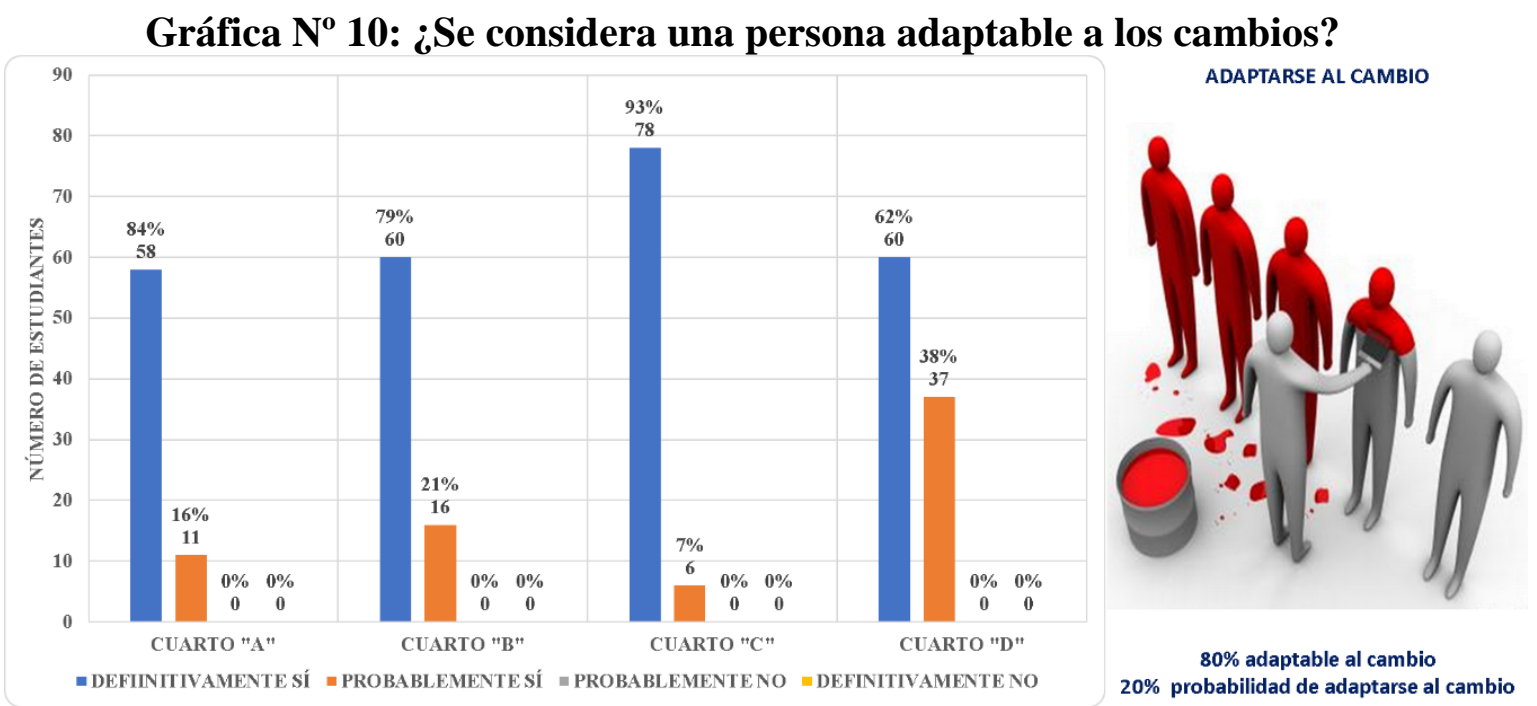

Fuente: Elaborado por el investigador.

\section{Proactividad como componente del espíritu emprendedor.}

La proactividad hace referencia a una actitud presente en algunas personas, que no permiten que las situaciones difíciles los superen. Toman la iniciativa sobre sus propias vidas y trabajan sobre aquello que creen que puede ayudarlos a estar mejor. En este sentido el $46 \%$ de los emprendedores de esta investigación poseen una clara idea acerca de lo que desea para su futuro. Esto permite ver que han desarrollado la capacidad de 
ver el camino hacia adelante y tomar acciones en el presente, para llegar a la meta establecida de un modo eficaz.
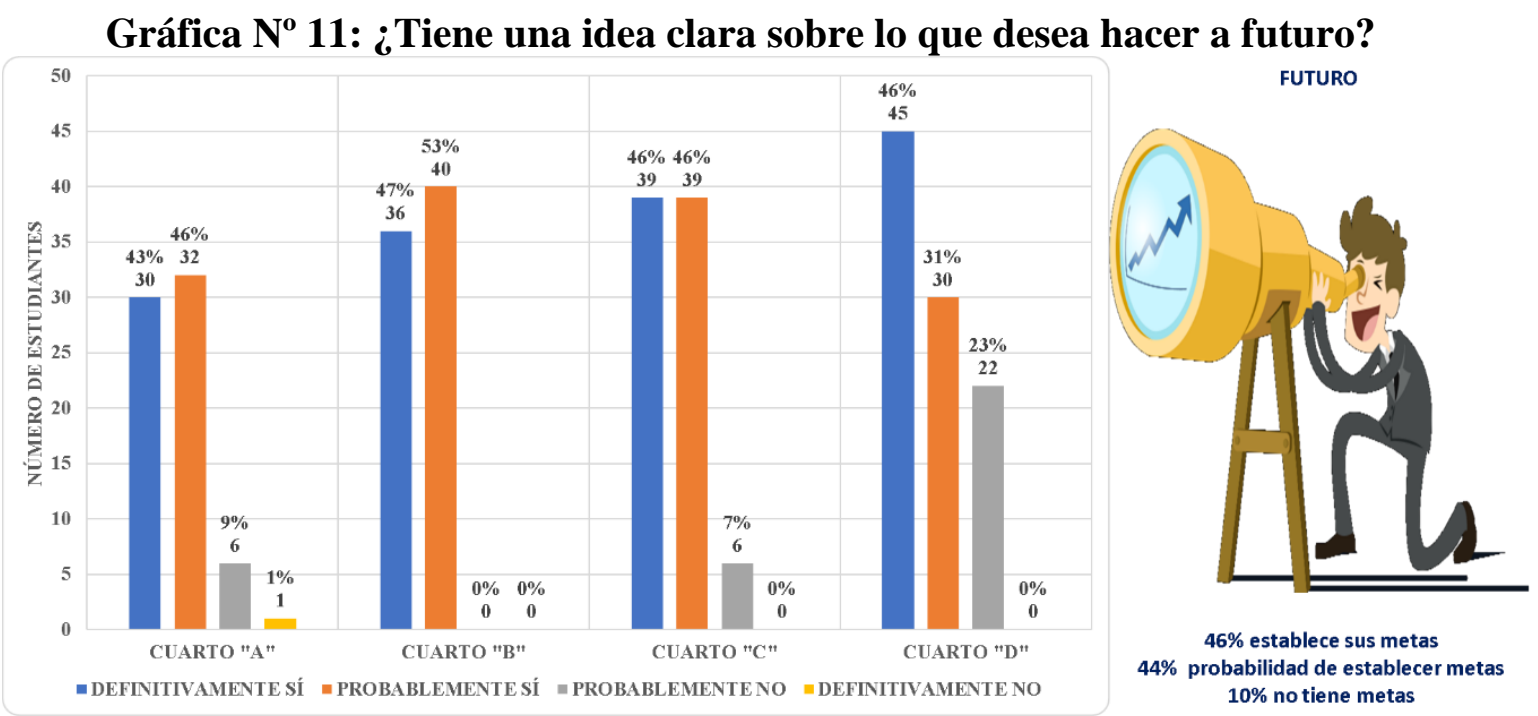

Fuente: Elaborado por el investigador.

El $46 \%$ de los emprendedores ha establecido sus metas a futuro actuando en el presente de modo eficaz. Un $44 \%$ presenta la probabilidad de hacerlo y el $10 \%$ restante no lo ha realizado aún.

La proactividad implica también desarrollar una actitud optimista, es decir mirar el lado positivo de cada hecho o acontecimiento que se presenten en el camino.

El optimismo permite encontrar soluciones, ventajas y posibilidades ante los inconvenientes surgidos.

En este caso, los emprendedores encuestados muestran un medio grado de optimismo y el 53\% de la muestra se encuentra capacitado para afrontar situaciones nuevas de la mejor manera posible.

Además de ello, el $63 \%$ de los encuestados tiene la habilidad de aprender de los errores y convertirlos en una nueva fuente de aprendizaje demostrando de ese modo otro rasgo fundamental como lo es la voluntad constante de aprender. 


\section{Gráfica Nº 12: ¿Afronta Los Problemas Con Optimismo?}

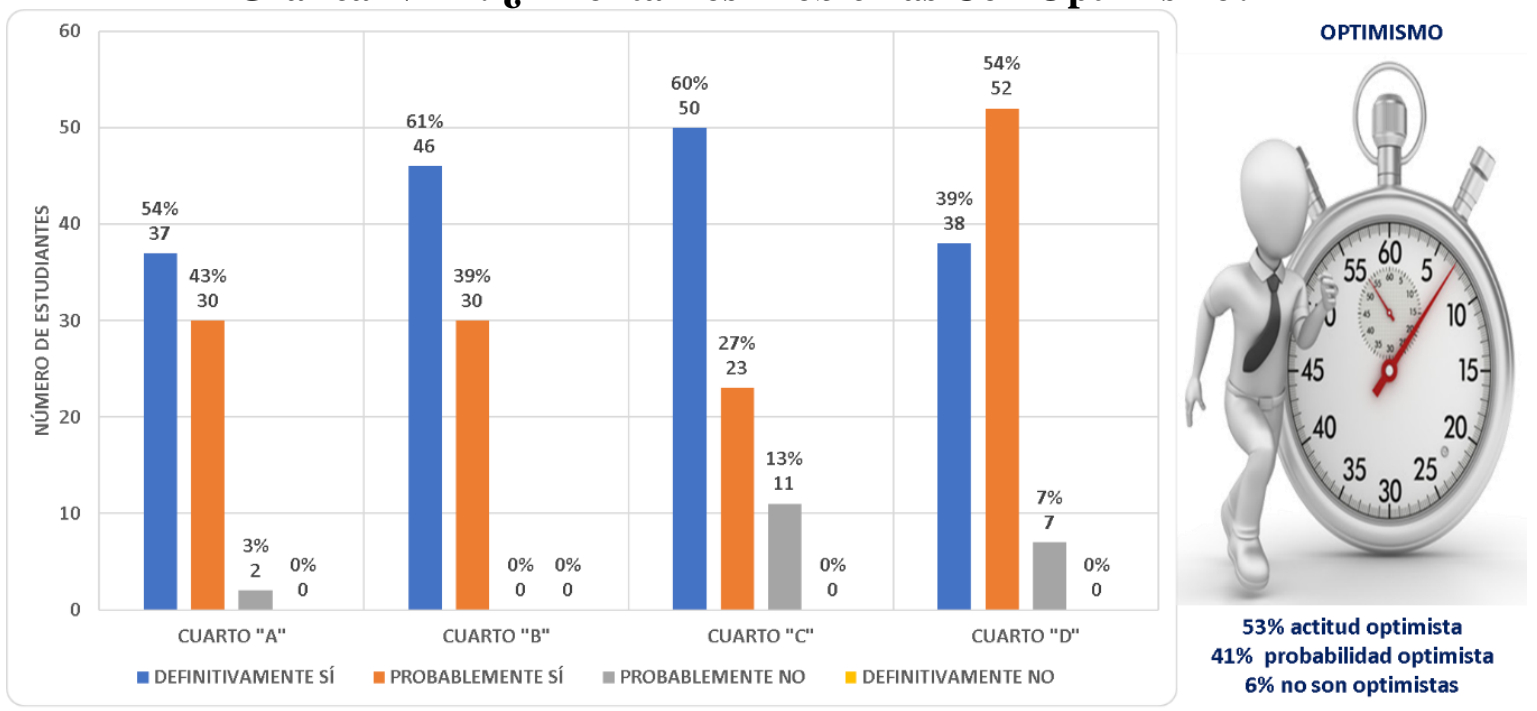

Fuente: Elaborado por el investigador.

A partir del gráfico puede apreciarse que el $53 \%$ de la muestra presenta una actitud optimista. El $41 \%$ probablemente manifiesta dicha actitud.

\section{Gráfica $\mathbf{N}^{\circ}$ 13: ¿Considera que es capaz de convertir sus errores en nuevos aprendizajes?}
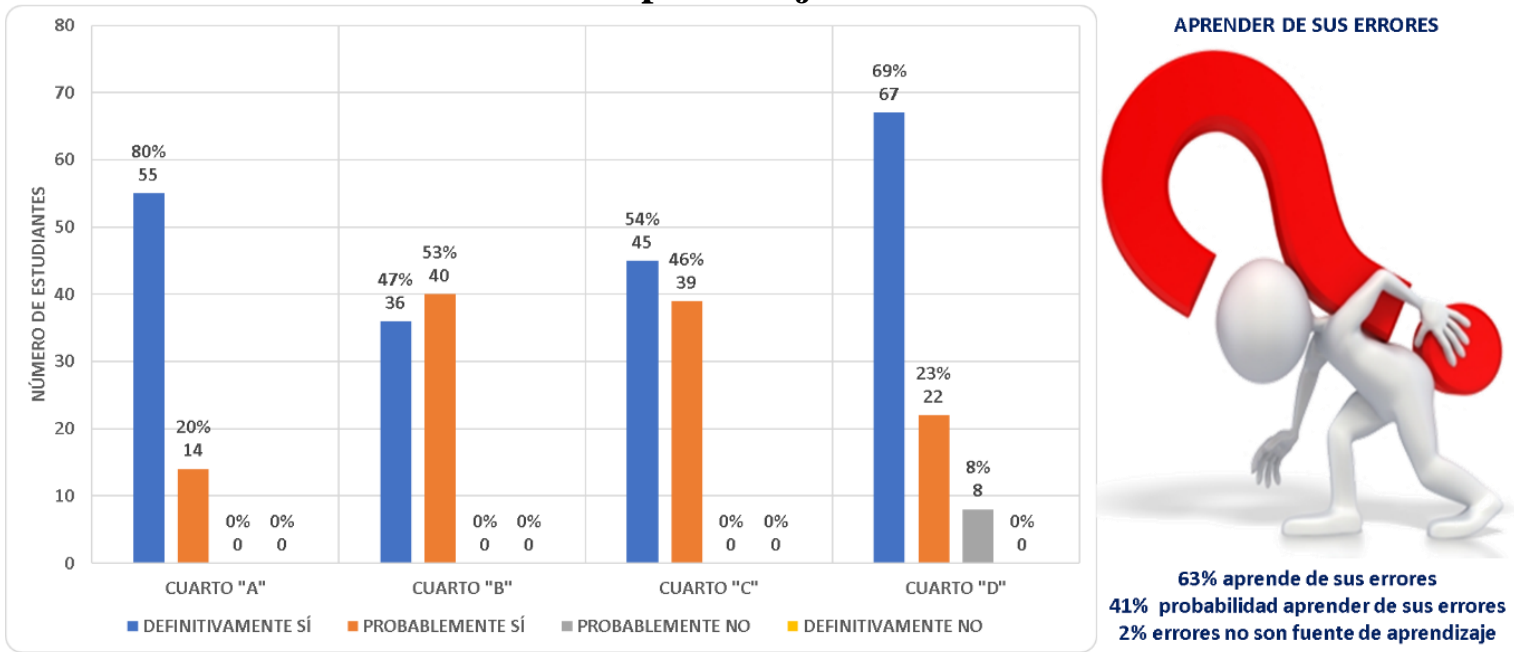

Fuente: Elaborado por el investigador.

En esta ocasión el $63 \%$ admite aprender de sus errores, el 35\% probablemente haya aprendido de sus errores y el $2 \%$ no ve a los erros como fuente de aprendizaje.

La actitud proactiva es entonces otro de los rasgos fundamentales del espíritu emprendedor y es también uno de los 7 hábitos de la gente altamente efectiva según Stephen Covey (2003). 


\section{Factores de influencia en la adquisición de las habilidades emprendedoras.}

La formación de los primeros años de vida de los sujetos puede influenciar el desarrollo de habilidades emprendedoras. La educación que se recibe en el hogar es fundamental para crear las bases de las capacidades, valores y habilidades necesarias para emprender. Además, cuando el desarrollo de un individuo tiene lugar en un ambiente empresarial que forma parte de su vida cotidiana, es probable que reciba un estímulo para imitar en el futuro el emprendedurismo de sus familiares.

Las respuestas brindadas por los emprendedores encuestados permiten afirmar dicha teoría ya que un $48 \%$ proviene de hogares donde se han desarrollado más de un emprendimiento.

Por otra parte, el $60 \%$ afirma que el apoyo de la familia a la hora de iniciar su emprendimiento ha sido fundamental.

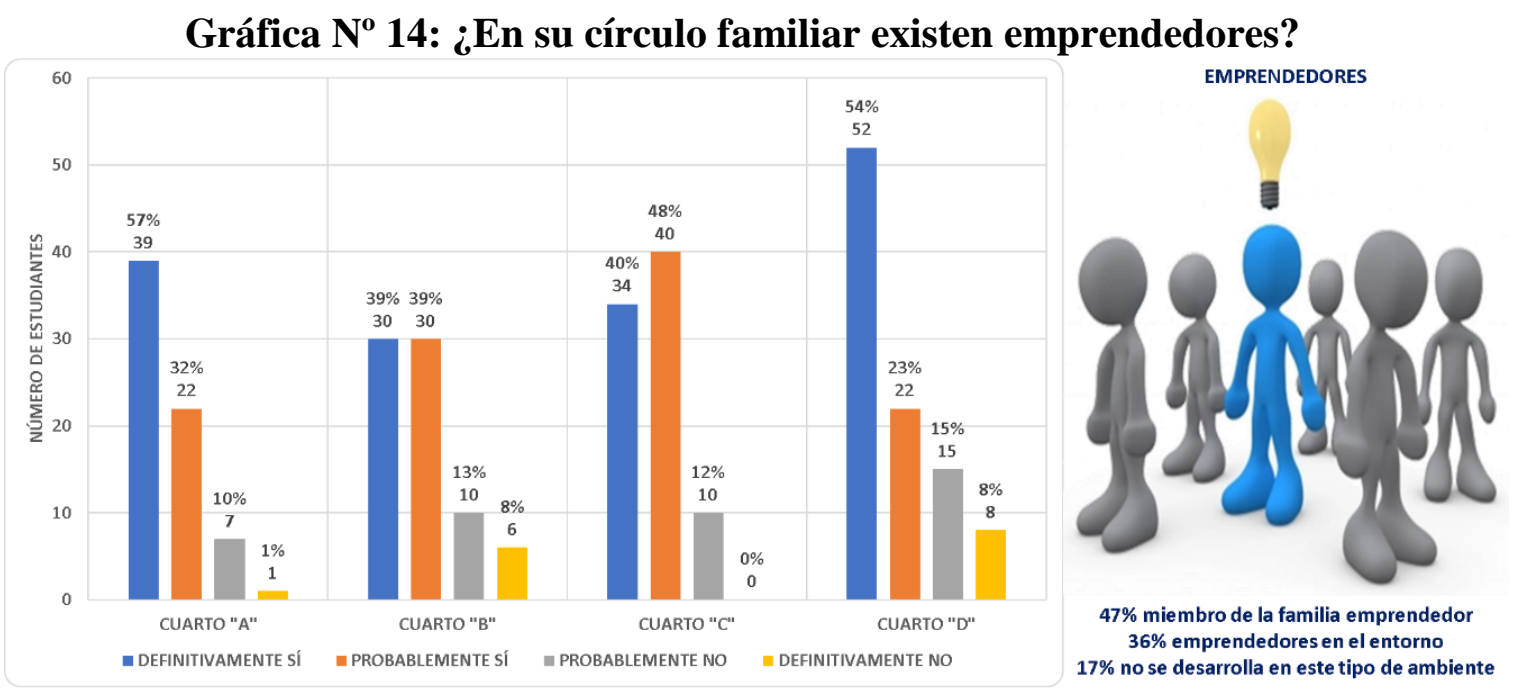

Fuente: Elaborado por el investigador.

El gráfico demuestra que el $47 \%$ de los encuestados ha crecido en un entorno donde alguno de los miembros de su familia es emprendedor. El $36 \%$ considera la probabilidad de que existan emprendedores en su entorno y $17 \%$ restante no se ha desarrollo en ese tipo de ambiente. 


\section{Gráfica $\mathrm{N}^{0}$ 15: ¿El apoyo de su familia fue importante al momento de emprender?}
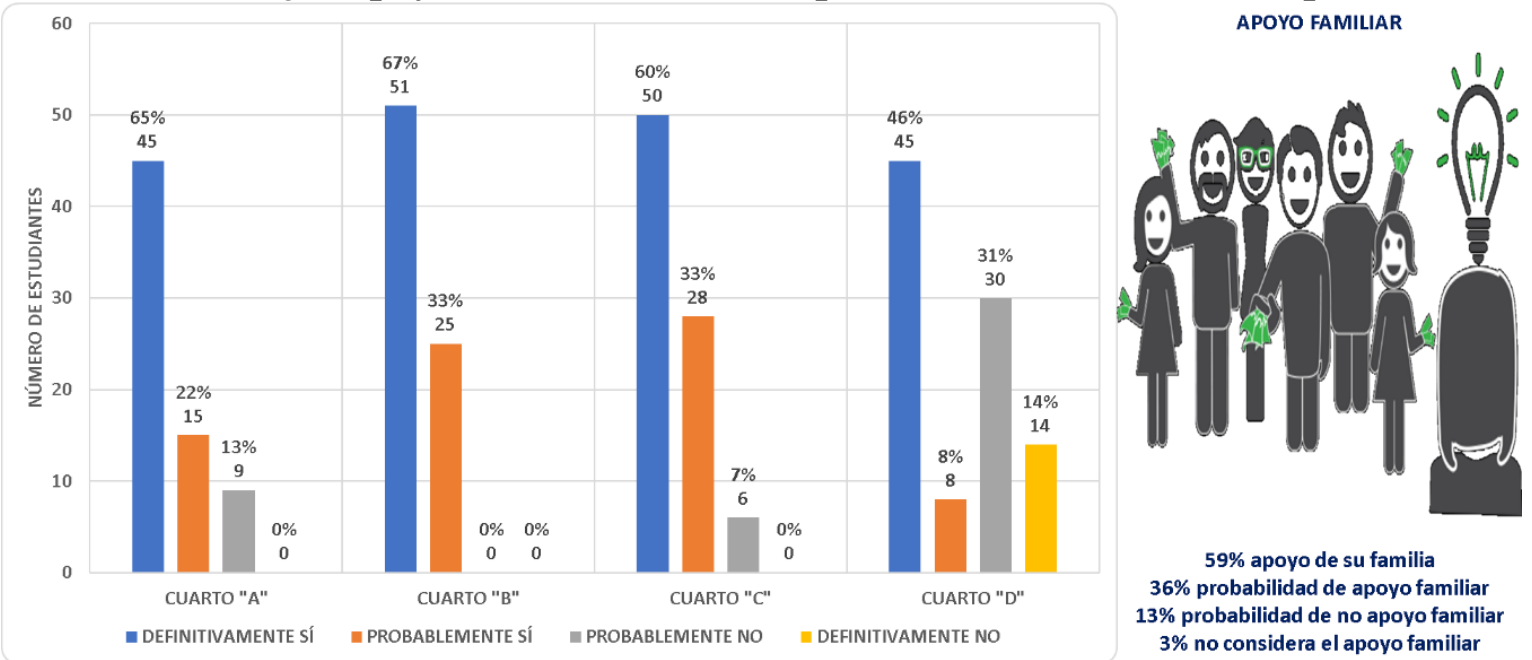

Fuente: Elaborado por el investigador.

El 59\% de la muestra considera que el apoyo de su familia es fundamental en lo que respecta a su desarrollo como emprendedor. Para el 36\% es probable que sea importante el apoyo familiar, un $13 \%$ presenta la presenta la probabilidad de que no sea importante y el 3\% de la muestra no considera el apoyo familiar como un factor influyente.

También es necesario destacar el hecho de que las habilidades y competencias que adquieren quienes se convierten en emprendedores son proporcionadas por el aprendizaje que la persona obtiene a lo largo de su existencia. Por ello el sistema educativo se torna un eje relevante para la promoción y desarrollo de dichas competencias y habilidades.

Respecto a ello, el 51\% de los emprendedores considera la formación académica que ha recibido a lo largo de su existencia como un factor clave para el desarrollo de su espíritu emprendedor.

\section{Gráfica $\mathbf{N}^{\circ}$ 16: ¿La formación académica que posee ha influido en el desarrollo de} su espíritu emprendedor?
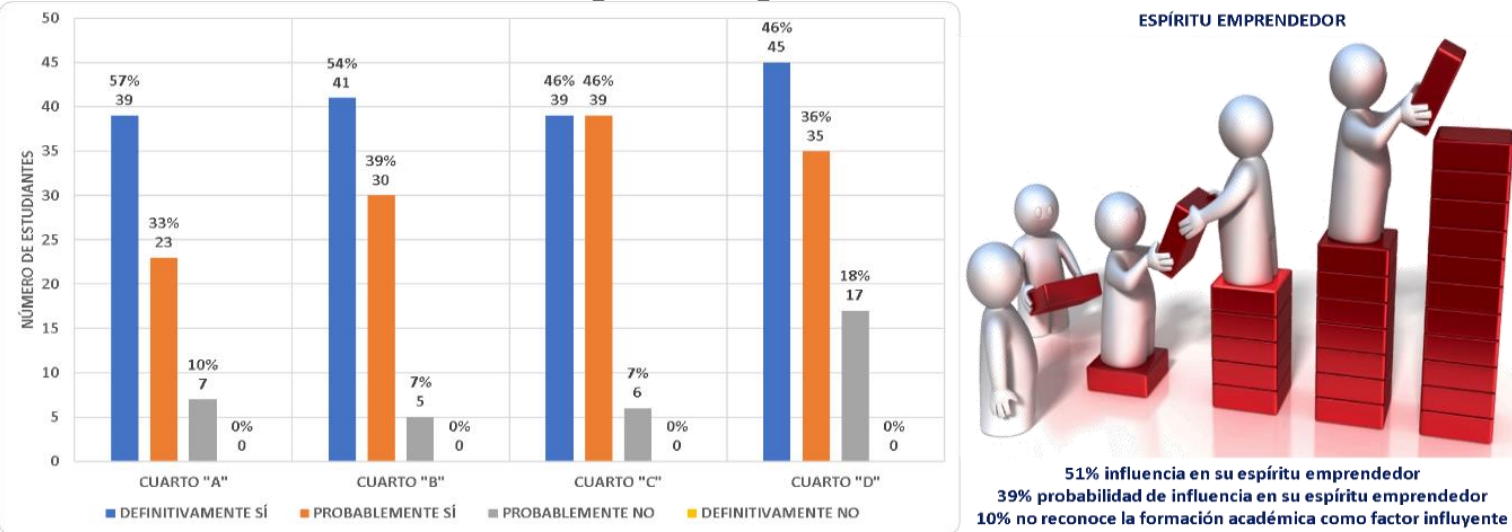

Fuente: Elaborado por el investigador. 
Del gráfico se desprende que, las respuestas se dividen entre aquellos que definitivamente consideran que ha influido en el desarrollo de su espíritu emprendedor $(51 \%)$ y aquellos que establecen una probabilidad respecto a que haya sido influyente en su formación emprendedora (39\%). El 10\% restante no reconoce a la formación académica como un factor influyente.

En conclusión, las competencias y habilidades emprendedoras se adquieren en una primera etapa de sociabilización a través la familia y además puede influir en ello el entorno en el que el individuo desarrolla. Si es un entorno de emprendedores es probable que el individuo tienda a imitar dicho comportamiento en el futuro. Luego en una segunda instancia de sociabilización aparece el sistema educativo como factor clave que modera y redefine dichas competencias y habilidades en el sujeto.

\section{Acciones para la promoción y desarrollo del espíritu emprendedor la cultura emprendedora en la Carrera de Administración de Empresas}

$\mathrm{Al}$ analizar las características de la personalidad de los estudiantes de último año de la Carrera de Administración de Empresas con espíritu emprendedor es necesario considerar que tienen una profunda relación con la cultura que los rodea ya que, como se establece en párrafos precedentes los elementos de la personalidad se adquieren en distintas etapas de sociabilización y en última instancia son moderados por la cultura que a través de valores y normas le indica a las personas lo que es deseable o no.

Aunque la información obtenida permite deducir la existencia del ecosistema emprendedor en la provincia en el cual se gestionan y articulan actividades en torno a los emprendedores, las respuestas que se obtienen a partir de la encuesta respecto al tema demuestran que sólo un 34\% de los estudiantes encuestados reconoció la presencia del mismo. El $46 \%$ presenta dudas estableciendo la probabilidad de su existencia. Un $13 \%$ establece la probabilidad de la no existencia del ecosistema y el $7 \%$ restante tiene la certeza de que no existe. 
Gráfica N 17: ¿Considera que la Carrera de Administración de Empresas forma parte del ecosistema emprendedor del Departamento de Chuquisaca?
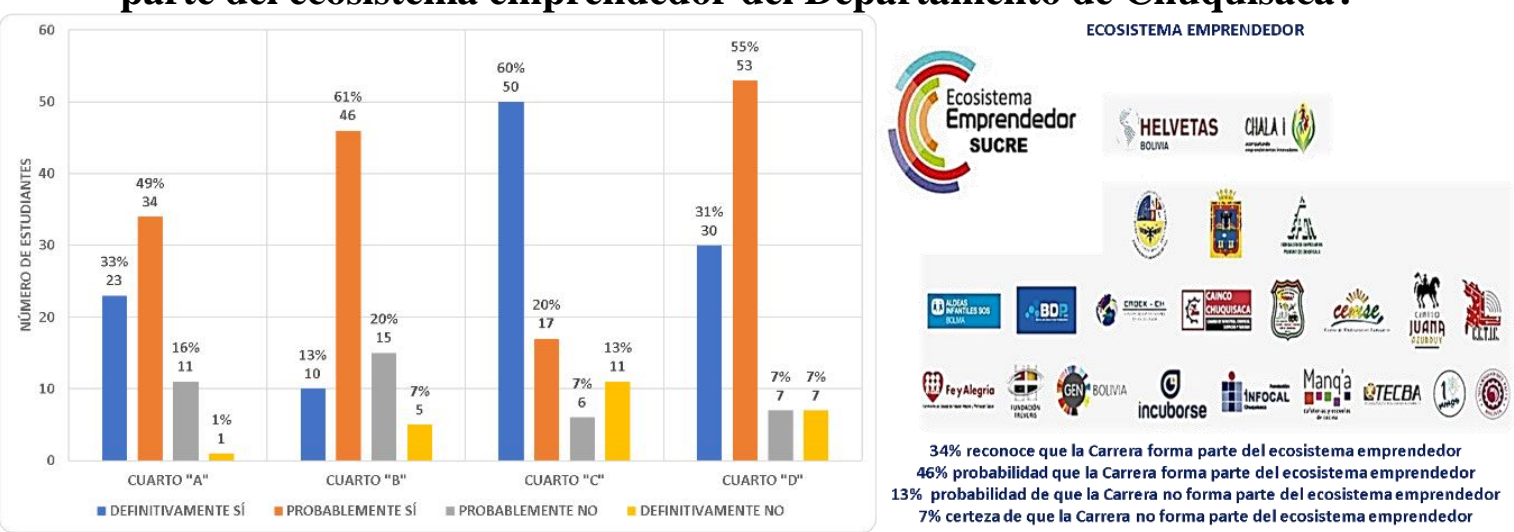

Fuente: Elaborado por el investigador.

No obstante, el $51 \%$ de los encuestados manifiestan el hecho de tener conocimiento respecto a las entidades, como fundaciones y organizaciones destinadas al desarrollo emprendedor que funcionan en la provincia acompañado de un $64 \%$ que considera que se realizan actividades para promocionar el espíritu emprendedor en la Carrera de Administración de Empresas.

\section{Gráfica No 18: ¿Cuenta la Carrera de Administración de Empresas con} organizaciones destinadas a la promoción del espíritu emprendedor?
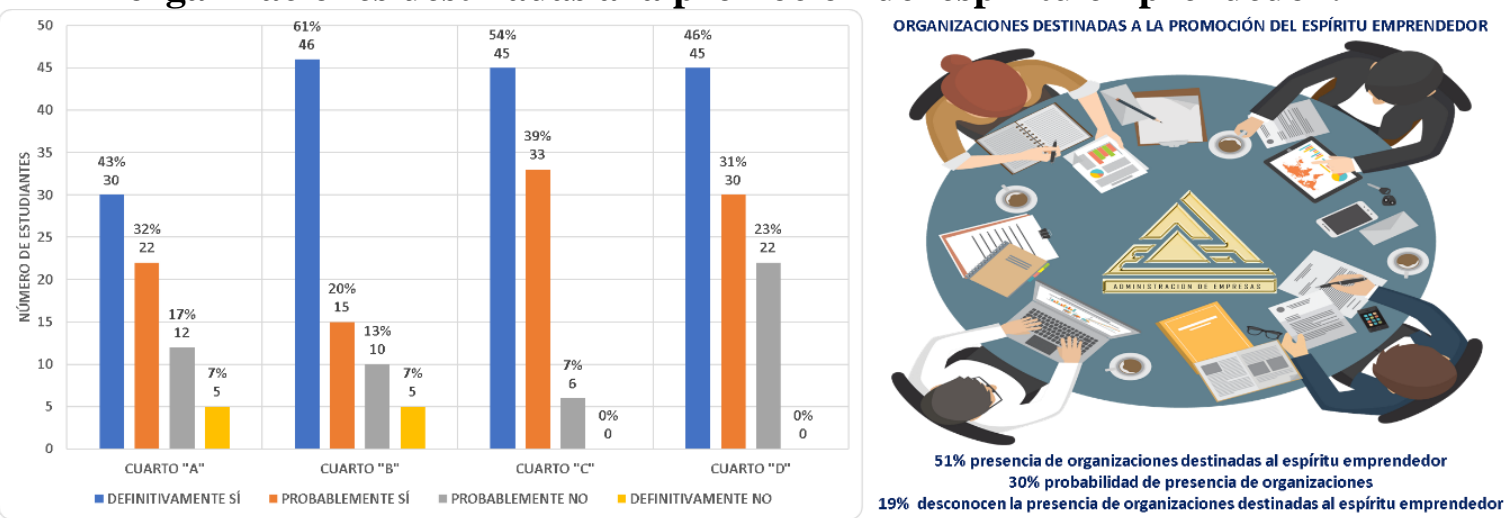

Fuente: Elaborado por el investigador.

Del total de respuestas, un $51 \%$ reconoce la presencia de entidades destinadas a promover el espíritu emprendedor. El 30\% considera la probabilidad de ello y el $15 \%$ y $4 \%$ restante demuestran desconocer la existencia de dichas organizaciones. 


\section{Gráfica $N^{\circ}$ 19: ¿Considera usted que se realizan actividades con el fin promover el espíritu emprendedor en la Carrera de Administración de Empresas?}
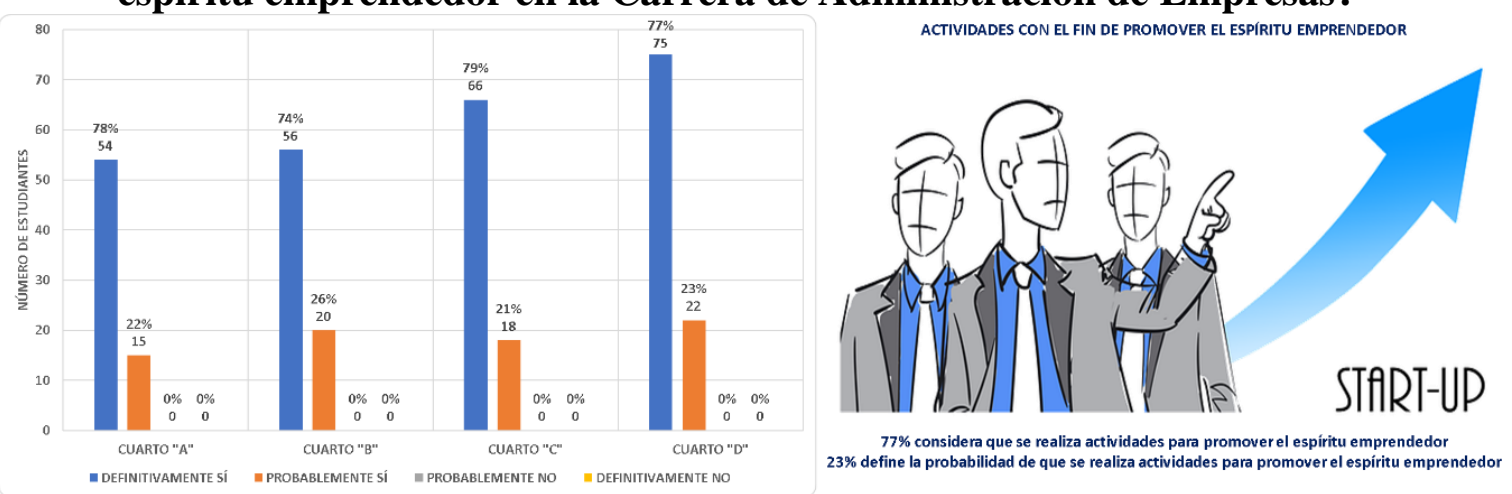

Fuente: Elaborado por el investigador.

El gráfico permite ver que el $77 \%$ de los encuestados considera que se realizan actividades de promoción y el 23\% define la probabilidad de que así sea.

En conclusión, se evidencia en los estudiantes bajo análisis un espíritu emprendedor cuyas principales características son la creatividad, la autoconfianza y la responsabilidad. Son personas proactivas, motivadas hacia la obtención de objetivos y capaces de tolerar situaciones de incertidumbre cuando se presentan posibles cambios.

La familia y la formación académica se presentan como factores claves en la adquisición de las habilidades emprendedoras.

Respecto al fomento de la cultura emprendedora, se advierte la presencia de instituciones destinadas a la promoción del espíritu emprendedor a través del aprendizaje y la experiencia.

Por su parte, desde el gobierno y también desde el Municipio de la Ciudad de Sucre se articulan y gestionan diversas acciones a fin de fortalecer el ecosistema emprendedor. El programa de la Carrera de Administración de Empresas marca una tendencia creciente de políticas públicas en favor del desarrollo del emprendedurismo.

Sin embargo, la existencia del ecosistema emprendedor no es reconocida por una parte de la población emprendedora. Ello puede deberse a su reciente surgimiento.

\section{CONCLUSIONES}

El presente trabajo de investigación concuerda con la definición del espíritu emprendedor porque no es una tarea sencilla, debido a que existen una diversidad y multiplicidad de características que poseen unas personas y otras no, pero que de cualquier modo los hace exitosos. 
Sin embargo, a partir de las variables analizadas es posible establecer que se evidencia en los estudiantes de último año de la Carrera de Administración de Empresas un alto desarrollo de las capacidades creativas junto con la autoconfianza. Además de ello, la población estudiantil estudiada tiene una clara visión respecto a la importancia de ser responsables en cuanto a la toma de decisiones y los objetivos de su emprendimiento.

Estas características son el soporte de todo emprendimiento, ya que la creatividad junto con la autoconfianza le permite desarrollar al individuo un comportamiento innovador, a partir de la creación de nuevas ideas. Por su parte, desde el ámbito organizacional, la responsabilidad juega un papel fundamental debido a que el emprendedor no sólo debe velar por su bienestar personal sino también procurar la promoción del bien común en el entorno en el cual se encuentre inserto.

Por otra parte, desde las habilidades sociales el espíritu emprendedor implica el desarrollo de un buen liderazgo y el trabajo en equipo. El liderazgo se presenta como una característica marcada en el grupo de emprendedores que participaron de la investigación, resaltando el desarrollo personal y profesional de su personal. En lo que respecta a la forma de trabajo, se encuentra una marcada tendencia hacia el trabajo en equipo de respuestas obtenidas respecto al tema.

En lo que respecta a la motivación de logro, que es entendida como la necesidad de perseguir y alcanzar objetivos y ascender en la escala del éxito, los estudiantes de la Carrera de Administración de Empresas se caracterizan por poseer un alto grado de motivación por la obtención de sus objetivos. Esta motivación está dada por la necesidad de obtener resultados satisfactorios toda vez que ejecuten su papel como emprendedor. En este sentido, al momento de iniciar un emprendimiento se advierte que en su mayoría son emprendimientos por oportunidad.

Entre dichos emprendimientos se destacan en primer lugar, lograr la realización personal, en segundo lugar, se emprende para aplicar conocimientos adquiridos y en tercer lugar los emprendimientos se han iniciado con el objetivo de autoemplearse.

Por último, respecto a las características personales del espíritu emprendedor se encuentra la actitud proactiva. En este sentido, es posible establecer que los estudiantes de la Carrera de Administración de Empresa de esta investigación poseen una clara idea acerca de lo que desea para su futuro. Esto permite ver que han desarrollado la capacidad de ver el camino hacia adelante y tomar acciones en el presente, para llegar a 
la meta establecida de un modo eficaz. Dos rasgos característicos de la actitud proactiva son el optimismo y la capacidad de aprender de los errores.

Respecto a la pregunta que ha guiado esta investigación acerca de si emprendedor se nace o se hace, la principal conclusión que se establece que, aunque existen capacidades emprendedoras que son innatas a las personas también hay otras que se pueden formar y desarrollar a través de fomentar un proceso de asociación entre el aprendizaje y la experiencia.

En esta instancia, la familia y el sistema universitario se convierten en ejes claves de la adquisición de las habilidades emprendedoras. En la presente investigación se aprecia que los estudiantes y el apoyo de la familia ha sido un factor clave en el desarrollo de su emprendimiento y además un \% ha crecido en un entorno de emprendedores. Por otra parte, para él un porcentaje de los emprendedores ha sido influyente su formación académica. Esto demuestra que el entorno en el que el sujeto ha crecido es de gran importancia para su formación emprendedora y la presencia del emprendedurismo en la familia ha sido en muchas ocasiones un factor motivacional.

Por último y para finalizar es importante establecer que para el desarrollo del espíritu emprendedor no basta con que los individuos cuenten con características de su personalidad adecuadas, sino que se requiere de una cultura que lo fomente.

Respecto a la presencia de un ecosistema emprendedor, actualmente, hay un ecosistema de emprendimiento en la ciudad de Sucre. Sin embargo, está lejos de ser un ecosistema prototipo de emprendimiento (ecosistema ejemplar o ideal). Eso por diferentes debilidades. En especial, por la falta de coordinación efectiva entre las instituciones que apoyan el emprendimiento en la capital.

Las principales fallas del ecosistema emprendedor en Sucre son la calidad de la educación y el capital humano, lo que provoca una elevada tasa de mortalidad en los nuevos emprendimientos. Lo que se debe demandar a las autoridades responsables de los organismos que intervienen en el ecosistema de emprendimiento es que planifiquen el trabajo de las áreas de inversión pública para que sean catalizadoras de futuras inversiones privadas, ya que estas son las unidades naturales de generación de desarrollo, fuentes de trabajo y bienestar en general. Se debe demandar que ese trabajo no se improvise, generando, más bien, competencia para las empresas ya establecidas en nuestra ciudad. 
Las organizaciones locales que apoyan los emprendimientos no articulan su trabajo entre sí y se limitan a dar capacitación, lo que incide en un entorno desfavorable para los emprendedores (Fundapro, 2015).

Para generar un ecosistema prototipo del emprendedor universitario en la ciudad de Sucre, por ejemplo, se requiere una coordinación eficiente entre la Universidad, el Gobierno y las empresas privadas. De esta manera, se podrá consolidar negocios.

Se deberán implementar, al mismo tiempo, políticas y regulaciones que generen condiciones favorables para el emprendimiento, incluyendo la formalización de la economía popular. También es primordial atacar los problemas de formación de recursos humanos, de institucionalidad y de construcción del tejido empresarial.

Un ecosistema prototipo está compuesto por emprendedores, instituciones académicas, Gobierno, instituciones privadas y organizaciones sin fines de lucro. Debe contar con infraestructura y redes de contacto, y, además, con el apoyo de las entidades financieras. Las principales fallas del ecosistema emprendedor en Sucre son la calidad de la educación y el capital humano, lo que provoca una elevada tasa de mortalidad en los nuevos emprendimientos, que no llegan a subsistir ni tres años, como se expuso en la revisión evaluativa.

La formación de los recursos humanos es deficiente y, además, el sistema educativo no prepara los talentos necesarios. Entonces, lo que falla es la cantera, buenos emprendedores y empresarios. Significa que no existe una masa crítica de investigadores e innovadores, capaces de crear empresas eficientes y sostenibles, incorporar las nuevas tecnologías y propulsar el cambio productivo. El resultado es un rezago educativo que lastra el capital humano y reduce las posibilidades de progresar en innovación y emprendimiento.

Sucre adolece de la debilidad de su estructura empresarial y también de su marcada heterogeneidad y un considerable grado de polarización entre un estrato pequeño de grandes y medianas empresas formales, con niveles de productividad y competitividad elevados, y un extenso conglomerado de micro y pequeñas empresas, mayormente informales y con niveles de productividad extremamente bajos. Son sectores independientes, lo que reduce las oportunidades de negocios, tercerización de procesos o vinculación con cadenas de valor. Se añade a ello, la todavía incipiente presencia de 
empresas innovadoras y de base tecnológica, como otro factor que frena el surgimiento de nuevas empresas y emprendedores dinámicos.

El reto de la ciudad de Sucre es resolver las carencias básicas para el desarrollo de capacidades y actividades emprendedoras robustas, innovadoras y con potencial de crecimiento.

Actualmente, la mayoría de las actividades emprendedoras son fruto de la falta de alternativas de empleo, y su resultado, consiguientemente, es la microempresa de subsistencia. Al no haber suficiente músculo emprendedor para crear e impulsar empresas dinámicas, los emprendimientos no consiguen crecer ni impactar sustantivamente sobre la generación de riqueza.

En conclusión, desde el aspecto personal, la promoción de la cultura emprendedora lleva consigo el fomento del espíritu emprendedor a los miembros de la empresa de la que forma parte. Las personas con espíritu emprendedor están dotadas de un espíritu innovador, tiene la voluntad de ensayar nuevas experiencias o hacer las cosas de manera diferente, simplemente por la existencia de posibilidades de cambio.

\section{REFERENCIAS BIBLIOGRÁFICAS}

(JICA), A. d. (2003). ESTUDIO EN EL AREA DEL DESARROLLO EMPRESARIAL. Buenos Aires.

Angelelli, \& Prats. (2005). Fomento de la actividad emprendedora en América Latina y el Caribe. Washington D.C.: Banco Interamericano de Desarrollo.

Anzola. (2001). Como desarrollar una verdadera actitud emprendedora. México: ITSEM Campus Monterrey.

Anzola. (2003). La actitud emprendedora. México: McGrawHill. came. (22 de junio de 2016). Obtenido de came: http://www.camejoven.org.ar/

Carbonell, S. d. (2016). GEM 2015 Resumen-Argentina. Buenos Aires: Centro de Entrepreneurship IAE Business School.

Carlos Ornelas, C. E., Liquidano Rodríguez, M. d., Contreras González, L. E., \& Silva Olvera, M. d. (2015). El Espíritu Emprendedor y un Factor que Influencia su Desarrollo Temprano. Conciencia Tecnológica, 46-51.

Paidós. (2003). Espíritu emprendedor. Guía del profesor. Madrid: Dirección General de Política de la Pequeña y Mediana Empresa. 
Furnham. (1995). Personalidad y diferencias individuales en el trabajo. Madrid: Pirámide.

Gobierno de Mendoza. (19 de Julio de 2016). Obtenido de Gobierno de Mendoza: http://www.prensa.mendoza.gov.ar

junior.org.ar. (30 de noviembre de 2016). Obtenido de junior.org.ar: http//www.junior.org.ar

Presentaron el ecosistema emprendedor de Mendoza. (19 de Julio de 2016). Mendoza, Mendoza, Argentina.

Rodrigo, V. (1996). Innovación empresarial, un enfoque de desarrollo. Colombia: ICESI.

Secretaría Pyme y Desarrollo Emprendedor del Ministerio de Industria, C. y. (octubre de 2014). Guía de políticas locales para promover el desarrollo emprendedor. Córdoba: autor.

Soy entrepreneur. (20 de junio de 2016). Obtenido de soy entrepreneur: http//www.soyentrepreneur.com Tondi, G. J. (2009). EVALUACION DE IMPACTO. Buenos Aires. Valvanera, C. F. (20 de marzo de 2010). www.eoi.es. Obtenido de www.eoi.es: http://www.eoi.es Varela. (1996). Innovación empresarial, un enfoque de desarrollo. Colombia: ICESI.

Vieytes, R. (2004). Metodología de la investigación en organizaciones, mercado y sociedad: epistemología y técnicas. Buenos Aires: Editorial de las Ciencias.

Chiavenato, I. (2007). Administración de Recursos Humanos. México: McGrawHill.

Covey, S. (2003). Los 7 Hábitos de la Gente Altamente Efectiva: La revolución ética en la vida cotidiana y en la empresa. Buenos Aires. 